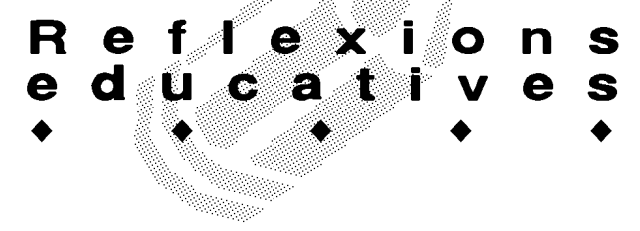

\title{
APRENDRE A EXPRESSAR INTENCIONS COMUNICATIVES A TRAVÉS DEL LLENGUATGE
}

\author{
Magda Rivero García. Àrea de Psicologia Evolutiva i de l'Educació. Universitat de Barcelona
}

Amb el present treball volem compartir amb la comunitat educativa alguns dels resultats de la investigació que hem dut a terme en els darrers anys sobre el desenvolupament inicial de la comunicació i del llenguatge. La nostra recerca s'ha realitzat amb infants petits, durant els primers divuit mesos de vida. Però molts dels plantejaments generals que l'han orientat $i$ dels resultats i conclusions que se'n deriven van més enllà d'aquest període d'edat en sentit estricte, i creiem que poden ajudar a donar pistes -o si més no, a motivar a la reflexió-sobre com enfocar l'acció educativa escolar i familiar amb l'objectiu de potenciar el millor desenvolupament comunicatiu i lingüístic dels infants.

Abans d'entrar més en matèria, fóra convenient recordar algunes idees en relació amb el llenguatge i posar de relleu des de quina orientació teòrica hem enfocat el nostre treball.

En primer lloc, cal recordar que el llenguatge és un sistema multifuncional i multidimensional. Multifuncional perquè és un sistema al qual corresponen funcions 0 usos diversos. Utilitzem el llenguatge per comunicarnos, per vehicular els aprenentatges i la cultura (usos socials o externs del llenguatge) i també per organitzar el mateix pensament o per planificar i regular la nostra activitat (usos individuals o interns). Multidimensional perquè es pot analitzar atenent diferents dimensions (fonològica/fonètica, morfosintàctica, semàntica i pragmàtica).

D'altra banda, cal explicitar que abordem l'estudi del desenvolupament comunicatiu i lingüístic des de la "perspectiva funcional-social". Des d'aquesta orientació es posa l'èmfasi en el llenguatge com a instrument de comunicació. Això porta a estudiar la parla infantil en el marc de les interaccions que mantenen els nens i els seus cuidadors, concedint una especial atenció a la dimensió pragmàtica, és a dir, als usos que es fan del llenguatge en situacions comunicatives en contextos socials. Entre els principals puntals de la fonamentació teòrica de la perspectiva funcional-social destaquen la teoria sociocultural de Vigotsky $(1977,1979)$ i les aportacions de lingüistes de la pragmàtica com Austin (1962), Grice (1975) o Searle (1969).
El desenvolupament pragmàtic es pot definir com "l'adquisició del coneixement necessari per a un ús de la parla en situacions interpersonals, apropiat, efectiu $i$ governat per regles" (NINIO i SNOW, 1996). El camp del desenvolupament pragmàtic inclou una àmplia gamma de fenòmens connectats amb el llenguatge i la interacció social, com ara el domini de les habilitats de conversa, l'adquisició de regles de cortesia i altres regles d'ús de la parla determinades culturalment, la utilització dels mecanismes que permeten estructurar un discurs cohesionat, els processos d'aprenentatge pragmàtic que operen en els inicis de l'adquisició del llenguatge, l'expressió d'intencions comunicatives, etc. És en aquest darrer tema, l'expressió d'intencions comunicatives, on ens centrarem en aquest treball.

Aprendre a expressar intencions comunicatives, és a dir, a fer propostes comunicatives, és una habilitat que els infants comencen a desenvolupar en el primer any de vida. Quan s'inicia l'ús de les primeres paraules, els infants ja han après a expressar un conjunt de propostes comunicatives 0 intencions a través de recursos no lingüístics (gestos, vocalizacions, mirades, somriures, accions...). Quan emeten les primeres paraules, es conceben a si mateixos $i$ als altres com a éssers intencionals i han desenvolupat habilitats d'atenció conjunta, com el seguiment de la direcció de la mirada i dels gestos de l'adult, la imitació d'accions sobre els objectes o la direcció de l'atenció de l'adult vers determinats aspectes de l'entorn a través del gest (CARPENTER, NAGELL i TOMASELLO, 1998). L'infant aprèn les paraules en situacions de comunicació en què prenen rellevància les intencions amb què s'emet la parla 0 , el que és el mateix, les propostes comunicatives que es transmeten a través del llenguatge. Els nens i les nenes miren de determinar en el context comunicatiu el propòsit que mou l'adult a emetre una determinada cadena de sons. Disposen d'experiència prèvia en la interpretació de les intencions que l'adult expressa no lingüísticament -com ara mostrar objectes 0 assenyalar-los-i poden emprar aquesta experiència per determinar la intenció comunicativa de l'adult i intentar delimitar en quin sentit una determinada paraula contribueix a l'expressió d'aquesta intenció. 


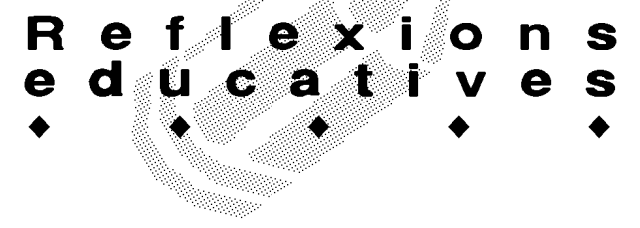

Els infants comencen a usar paraules per expressar intencions comunicatives. El coneixement que construeixen es podria formalitzar en termes de regles de correspondència entre intencions o propostes comunicatives, d'una banda, i formes d'expressió verbal de l'altra. Aprenen aquestes regles en el context de la interacció amb els adults (BRUNER, 1985; NINIO i SNOW, 1996). Arribaran a emprar aquelles regles de correspondència que l'adult utilitza en la seva interacció amb ells, en la mesura en què els seus recursos cognitius, lingüístics i socials ho permetin. L'adquisició del lèxic inicial es conceptualitza, des d'aquesta perspectiva, fonamentalment com un procés d'aprenentatge pragmàtic.

L'aprenentatge d'aquestes regles de correspondència no és un procés d'imitació basat en l'associació entre estímuls, sinó un procés de caràcter constructiu que es fonamenta en habilitats sociocognitives de certa complexitat i que Tomasello (2000) ha denominat "imitació de rol reversible". La imitació de rol reversible es fonamenta en les habilitats d'atenció conjunta i d'atribució d'intencions. Quan l'infant sent que l'adult emet una paraula -o un enunciat més llarg- no interpreta simplement que la parla adulta es relaciona amb algun element o aspecte de l'entorn. L'infant interpreta les intencions de l'adult en relació amb l'entorn, però també, i sobretot, les intencions de l'adult en relació amb ell (amb l'infant), i més concretament en relació amb els seus estats atencionals i intencionals. La paraula -o la parla-s'adreça a algú per influir en el seu estat atencional i intencional. L'infant, per aprendre a usar una paraula que sent a l'adult, ha de revertir els papers i usar la paraula per expressar la intenció comunicativa -en relació amb l'adult- que l'adult ha transmès en relació amb ell. La "imitació de rol reversible" és una forma específica d'aprenentatge sociocultural. Així, per exemple, quan l'adult diu a l'infant "vinga, al llit", aquest no només interpreta que l'adult està parlant del llit, sinó que interpreta que l'adult intenta que ell vagi al llit. De manera que quan sigui l'infant qui prengui la iniciativa d'anar a dormir, emprarà la paraula "lit" per aconseguir que l'adult li porti, és a dir, per modificar les seves intencions.

Podem afirmar que el context fa possible que l'infant accedeixi al significat que l'emissor d'un enunciat ha intentat expressar. Entendre, a un cert nivell, els principis sobre els quals opera la comunicació és un prerequeriment per poder atribuir sentit a les paraules noves que l'adult emet. Per poder accedir al significat de les paraules, l'infant ha de poder comprendre els tipus d'actes comunicatius en els quals aquestes apareixen.

L'adquisició del llenguatge, des d'aquesta perspectiva, és un procés en el qual els adults que tenen cura de l'infant juguen un paper fonamental, en la mesura que estructuren socialment i culturalment els contextos d'interacció, i proporcionen a l'infant suports i ajudes específics per al desenvolupament comunicatiu i lingüístic.

\section{L'ajuda adulta per al desenvolupament comunicatiu i lingüístic}

Els bebès s'integren en el sistema social gràcies al fet que els adults els faciliten la participació en situacions en les quals ofereixen els ajuts i suports necessaris perquè la interacció funcioni a un nivell superior del que fóra possible atenent estrictament les competències infantils. Els cuidadors creen i organitzen un microcosmos o marc de referència i donen sentit a les accions de l'infant (KAYE, 1982).

Quan un adult i un nen interactuen, sobretot si aquest darrer és un bebè, parteixen de diferents definicions de la situació en la qual estan implicats. L'adult ofereix suport i ajuts, i duu a terme els ajustos necessaris per fer possible la participació del nen en el context interactiu, intentant aproximar la definició infantil de la situació a la seva definició sociocultural.

Centrant-nos més directament en el desenvolupament comunicatiu i lingüístic, el procés es veu facilitat per la interacció social en virtut dels suports oferts pel participant més competent. L'ajut adult no s'ha d'entendre en el sentit d'una mera estimulació, sinó d'una manera més profunda, que remet a una idea de constructivisme social.

Lock (1980) destaca la importància de l'adult com a atribuïdor d'intencions. Si bé des del naixement el bebè manifesta una motivació vers la interacció humana, inicialment no transmet propostes comunicatives d'una manera intencional. L'adult pressuposa que el bebè intenta expressar algun significat i comunicar-se intencionalment $\mathrm{amb}$ ell $\mathrm{i}$ interpreta les seves conductes

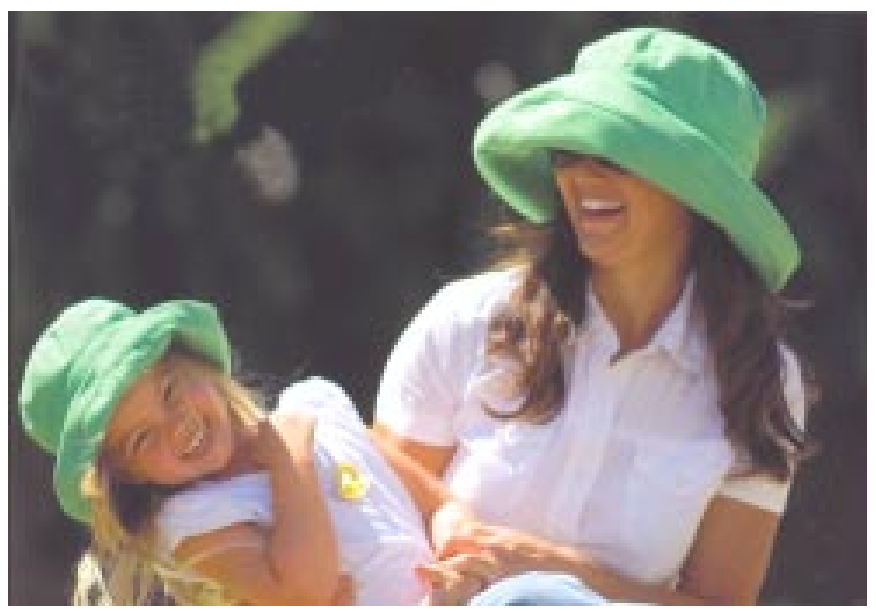




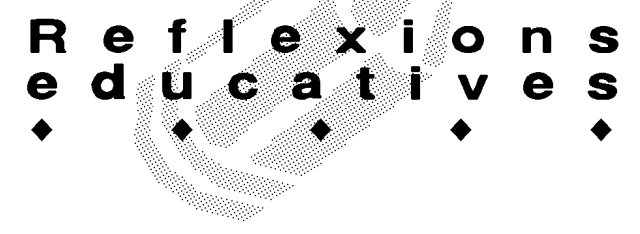

dotant-les d'un significat i una intenció culturalment apropiats. Amb aquesta atribució, que seria en realitat una sobreatribució, l'adult posa a disposició de l'infant els significats culturals i contribueix al fet que aquest darrer esdevingui conscient que les intencions es poden comunicar entre individus. D'altra banda, l'adult transmet a l'infant els procediments convencionals per a la comunicació humana, que són fonamentalment els que proporciona el llenguatge.

Intentant avançar en l'estudi de l'ajut social per al desenvolupament comunicatiu i lingüístic, trobem una important línia de recerca que vincula aquest desenvolupament amb aspectes específics i diferencials de la parla que els adults adrecen als nens petits en el context dels processos d'interacció.

Els estudis sobre la parla que els adults adrecen als infants que inicien el procés d'adquisició del llenguatge, denominada parla adreçada a l'infant o parla d'estil matern, han posat en evidència importants diferències entre aquesta parla i la pròpia de les converses entre adults. Aquestes característiques diferencials, que comentarem tot seguit, han estat observades tant en la parla de les mares com en la del pares, així com també en la parla que adrecen als nens petits els adults que no tenen fills $i / o$ que tenen poca experiència amb infants. Les característiques diferencials de la parla dirigida a l'infant han estat constatades en una àmplia gamma de llengües. No obstant això, la parla d'estil matern no és un fenomen totalment universal. Les formes en què les cultures organitzen els intercanvis comunicatius amb els infants varien àmpliament de comunitat a comunitat.

Entre les principals característiques diferencials de la parla adreçada als infants, destaquen certs trets referits a paràmetres suprasegmentals de la parla, com l'elevació del to de veu, l'exageració dels contorns prosòdics, el major ventall de freqüències o l'alentiment del ritme.

Una altra particularitat de la parla d'estil matern, ara ja de caràcter morfosintàctic, és la simplicitat. Aquesta es valora recorrent a mesures com la longitud mitjana de l'enunciat, la proporció de subordinades o la freqüència d'auxiliars del verb. La parla d'estil matern també es caracteritza per un elevat nivell de redundància, valorada amb indicadors com l'autorepetició immediata de la pròpia parla o la repetició de les mateixes paraules o frases en un període curt de temps.

Pel que fa a la semàntica i al lèxic, en la parla d'estil matern predominen les referències als objectes, persones, accions i esdeveniments de l'entorn immediat. La parla adreçada a l'infant està molt lligada al focus d'atenció del nen o a l'activitat conjunta amb l'adult.

En relació amb l'anàlisi pragmàtica de la parla adreçada a l'infant, la informació disponible és més aviat escassa. No obstant això, els estudis realitzats evidencien que els adults, quan s'adrecen als infants que estan aprenent a parlar, també realitzen modificacions en l'esfera pragmàtica. Així, pel que fa a la presa de torns, els treballs ja clàssics d'Snow (1977) van mostrar que mentre que en les converses adultes un objectiu primordial dels parlants és prendre el torn, l'objectiu principal de les converses adult-bebè és aconseguir que sigui l'infant qui el prengui, és a dir, propiciar la participació infantil.

Pel que fa a les intencions comunicatives expressades a través de la parla, Pan, Imbens-Bailey, Winner i Snow (1996) conclouen, arran de les seves investigacions, que els pares, quan interactuen amb els infants, seleccionen aquelles intencions comunicatives que aquests poden comprendre. El seu estudi longitudinal, realitzat amb cinquanta-dues parelles adult-nen/a observades durant el joc als catorze, vint i trenta-dos mesos d'edat de l'infant, va posar de manifest que als catorze mesos les mares -la pràctica totalitat dels adults eren les mares- expressaven un reduït nombre d'intencions comunicatives en la seva interacció amb el seu fill o filla. La varietat de les intencions comunicatives va anar en augment amb l'edat. Un altre resultat de l'estudi va ser que la utilització per part dels adults de directives disminuïa amb l'edat de l'infant. Aquests resultats posen de manifest que la parla que els adults adrecen als nens que estan aprenent la llengua està simplificada pragmàticament, de la mateixa manera que ho està sintàcticament i semànticament.

També cal destacar un altre grup de característiques que podríem denominar "particularitats discursives" de la parla adreçada a l'infant. Entre aquestes característiques podem assenyalar l'aparició d'expansions (l'adult reprèn l'enunciat previ de l'infant i l'amplia sense modificar-ne bàsicament el significat), d'extensions semàntiques (l'adult reprèn l'enunciat previ de l'infant i l'amplia introduint-hi algun nou element de significat), de correccions implícites (l'adult reformula correctament l'enunciat de l'infant sense feedback negatiu) o d'imitacions de la parla infantil, entre d'altres. Aquestes actuacions adultes, que també han estat denominades "estratègies educatives implícites" són freqüents en la parla d'estil matern.

Si parem tanta atenció sobre el conjunt de les característiques pròpies de la parla adreçada als infants, és perquè creiem que juguen un paper facilitador del procés d'adquisició del llenguatge. Cal assenyalar que les característiques pròpies de la parla d'estil matern no són immutables, sinó que es modifiquen en funció de variables relatives a l'infant, com ara l'edat o el nivell de competència comunicativa i lingüística, i de variables 


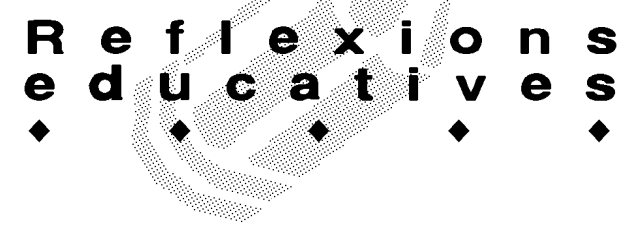

relatives a la interacció, com ara la resposta del nen. Aquest fet és el que es coneix com "ajustos de la parla d'estil matern".

\section{Algunes aportacions del nostre estudi}

Els subjectes del nostre estudi són tres parelles mare-fill/a que formen part d'una recerca longitudinal/ observacional en la qual es van registrar amb videocàmera activitats quotidianes d'interacció en context familiar. La llengua dels subjectes és el castellà, en el cas de la Sara i el Raúl, i el català en el cas de la Maria. Les dades a què ens referirem en aquest treball corresponen a l'activitat dels àpats.

\section{Un apunt sobre les intencions comunicatives ex- pressades pels infants a la primera infància}

Una conclusió general del nostre treball en relació amb aquest punt és que la gamma d'intencions comunicatives expressades pels infants es mostra relativament àmplia -molt àmplia quan apareixen les primeres paraules- quan s'utilitza un sistema de categories prou fi com per tenir en compte tant la producció infantil (gest, vocalització, paraula...) com el context interactiu en el qual es produeix i les metes de la interacció.

A manera d'exemple, la taula 1 mostra les intencions comunicatives que els tres infants del nostre estudi -com a grup- van expressar en l'etapa prelingüística, és a dir, abans de l'emissió de les primeres paraules.

Aquest repertori d'intencions comunicatives s'amplia considerablement amb la aparició de les primeres paraules. Donat que la llista d'intencions expressades lingüísticament és molt llarga, en presentarem només un tipus particular: les que apareixen en intercanvis comunicatius que tenen com a finalitat la "negociació de l'activitat immediata".

Si analitzem com es configura la gamma d'intencions comunicatives expressades pels infants al llarg del seu desenvolupament, observem, en la línia dels resultats obtinguts en els treballs de Ninio (1993) i Snow, Pan, Imbens-Bailey i Herman (1996), que les intencions comunicatives més lligades al context immediat apareixen abans que d'altres que suposen més distanciament del mateix context. Globalment, les primeres intencions comunicatives que els infants del nostre estudi expressen es relacionen amb negociar l'activitat immediata. Entre les primeres intencions comunicatives expressades apareixen també expressar malestar i executar un moviment o pas en un joc. Posteriorment els infants expressen intencions que suposen un cert distanciament del context immediat, com ara indicar la transferència d'un objecte per aconseguir l'ajuda de l'altre en relació amb el mateix objecte, exclamar-se en relació amb un esdeveniment recent, fer un comentari sobre el focus d'atenció/acció, respondre negativament a una pregunta sobre l'estat intern del destinatari o exclamar disgust per un esdeveniment desafortunat relacionat amb el focus d'atenció/ acció conjunta. Algunes de les intencions comunicatives que apareixen més tard mostren un major distanciament del context immediat. És el cas d'exclamar-se amb entusiasme en relació amb algú o amb alguna cosa no present, acceptar la marxa momentània de l'altre, respondre afirmativament a una pregunta destinada a aclarir el significat d'un comportament no verbal o respondre afirmativament a una pregunta destinada a aclarir el significat d'un enunciat.

Un altre dels resultats que ens semblen interessants té a veure amb els recursos formals o procediments

- Demanar un objecte.

(Ex.: La Maria a l'edat de 0;9.0: mira un tovalló; després mira la mare i crida.

Després mira el tovalló un altre cop, intenta agafar-lo i plora).

- Expressar el desig d'iniciar l'activitat. (Ex.: El Raúl a l'edat de 0;9.13: mira el menjar, ploriqueja i mostra agitació corporal).

- Expressar el desig de continuar l'activitat en curs. (Ex.: La Maria a l'edat de 0;10.18: mira el menjar i ploriqueja).

- Protestar per la interrupció de l'activitat en curs. (Ex.: La Sara a l'edat de 0;9.14: mira el menjar, rondinant).

- Rebutjar la proposta de continuar l'activitat en curs. (Ex.: La Sara a l'edat de 0;9.14: aparta la cullera, ploriquejant).

- Rebutjar l'acabament de l'activitat. (Ex.: El Raúl a l'edat de 0;10.14: mira el menjar, mostra agitació corporal i vocalitza -e::.: amb entonació ascendent).

- Rebutjar la proposta de l'altre de dur a terme una acció o de dur-la a terme d'una determinada manera. (Ex.: La Maria a l'edat de 0;9.0: vocalitza-mam, ma-, intentant aixecar-se, ploriquejant. Després plora).

- Demanar ajuda.

(Ex.: La Maria a l'edat de 0;9.0: mira la mare, vocalitzant -mama, mam- i estenent els braços $i$ orientant el cos vers ella).

- Executar un moviment o pas en un joc. (Ex.: La Sara a l'edat de 0;10.14: pica a la taula, com si fos en una porta).

- Expressar malestar.

(Ex.: La Maria a l'edat de 0;9.0: mira la càmera, ploriquejant).

Taula 1. Intencions comunicatives expressades pels infants -com a grup- durant l'etapa prelingüística. 


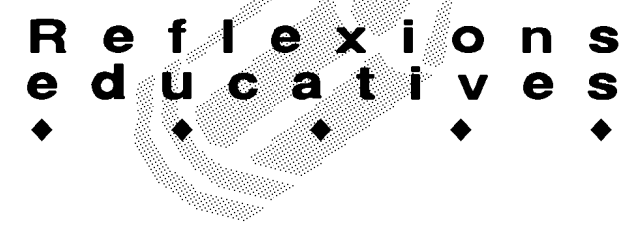

utilitzats pels infants per expressar les seves intencions comunicatives. Al llarg del període d'estudi algunes de les intencions varen ser expressades únicament a través de recursos no lingüístics (vocalitzacions, gestos...), mentre que d'altres ho varen ser exclusivament a través d'actes comunicatius que incorporen l'ús d'una paraula. D'altres intencions comunicatives varen aparèixer tant en actes comunicatius prelingüístics com lingüístics. Així doncs, les nostres dades avalarien una hipòtesi de continuïtat moderada entre la comunicació prelingüística i les primeres paraules. Algunes de les intencions comunicatives que els infants expressen a través d'actes comunicatius no lingüístics s'expressen amb posterioritat a través del llenguatge. D'altra banda, algunes de les primeres paraules també expressen intencions comunicatives noves. Algunes d'aquestes intencions, com ara per exemple fer un comentari sobre alguna cosa o sobre algú no present, o declarar la intenció de realitzar una determinada acció en el futur immediat, són difícilment expressables per mitjans no lingüístics. I en aquest sentit, l'adquisició del llenguatge obre noves possibilitats de comunicació.

Més enllà d'aquestes tendències generals, les dades mostren importants diferències individuals. El nombre total d'intencions comunicatives diferents expressades al llarg del període estudiat, el que podríem denominar el "repertori intencional" dels infants o la varietat de les seves propostes comunicatives, és molt diferent en els tres casos. D'altra banda, un dels subjectes, el Raúl, no arriba a expressar intencions comunicatives que suposin distanciament del context immediat.

També hem pogut identificar diferències importants entre els infants pel que fa a la forma d'expressar les intencions. La Sara presenta, al llarg del període estudiat, una distribució força equilibrada entre intencions comunicatives expressades per procediments no lingüístics (gestos, vocalitzacions...) i intencions expressades en actes comunicatius que incorporen una paraula. El perfil de la Maria és sensiblement diferent en aquest sentit. Globalment, en el període d'edat estudiat, són més les intencions comunicatives que expressa lingüísticament que les expressades en actes comunicatius no lingüístics. A partir dels 15 mesos, la majoria de les intencions comunicatives que passen a formar part del seu repertori estan associades a actes comunicatius que incorporen una paraula i, per tant, a l'adquisició de lèxic. Per a la Maria els procediments comunicatius no lingüístics continuen sent útils per a l'expressió d'intencions, però a partir de certa edat l'ampliació de la gamma d'intencions està associada a l'adquisició de paraules. Fer noves propostes comunicatives passa per adquirir noves paraules. El Raúl presenta un perfil clarament diferenciat dels dos anteriors, ja que en el seu cas l'expressió d'intencions comunicatives en el període estudiat es realitza pràcticament de manera exclusiva a través de recursos no lingüístics. El seu desenvolupament lexical al final del període estudiat és considerablement menor que el de la Sara i la Maria.

Les nostres dades suggereixen que les diferències identificades entre els subjectes tindrien a veure, almenys en part, amb l'estil interactiu de les mares, amb el suport que donen al desenvolupament comunicatiu i lingüístic dels infants i amb les característiques de la parla que adrecen als seus fills.

\section{Ajustos pragmàtics materns}

En relació amb aquest punt ens referirem a les dades obtingudes a partir de l'anàlisi de la parla de la mare de la Sara en la interacció amb la seva filla. L'aspecte que volem destacar és que, de la mateixa manera que s'ha pogut comprovar en nombrosos estudis, que les mares adapten les característiques formals (morfosintaxi) i lexicals/semàntiques (tipus de vocabulari, diversitat del lèxic...) de la seva parla en funció de variables com l'edat del nen o les seves competències comunicatives i lingüístiques, les nostres dades posen de manifest que les mares també realitzen ajustos de caràcter pragmàtic. Com ja hem dit, aquest darrer tipus

- Acceptar la prohibició de dur a terme una acció o de dur-la a terme d'una manera determinada.

- Acceptar la proposta d'iniciar l'activitat.

- Proposar l'inici d'una nova activitat.

- Declarar la intenció de fer una acció determinada en el futur immediat.

- Expressar el desig de continuar l'activitat en curs.

- Rebutjar la proposta de continuar l'activitat en curs.

- Indicar la transferència d'un objecte per aconseguir l'ajuda de l'altre en relació amb el mateix objecte.

- Acceptar la proposta de l'altre de dur a terme una acció o de dur-la a terme d'una manera determinada.

- Rebutjar la proposta de l'altre de dur a terme una acció o de dur-la a terme d'una manera determinada.

- Proposar a l'altre que dugui a terme una acció o que la dugui a terme d'una manera determinada.

- Proposar un nou focus per a l'activitat.

- Demanar un objecte.

- Demanar ajuda.

- Rebutjar l'oferiment d'ajuda.

- Expressar el desig de donar per acabada l'activitat.

- Dirigir l'atenció de l'altre vers un objecte per aconseguir que aquell actuï sobre el mateix objecte.

- Respondre negativament a un requeriment d'objecte.

Taula 2. Intencions comunicatives expressades lingüísticament pels infants en intercanvis adreçats a negociar l'activitat immediata. 


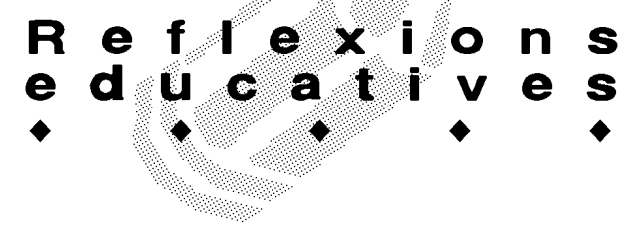

d'ajustos han estat menys estudiats, i en aquest sentit el nostre treball realitza algunes aportacions.

D'entre els ajustos pragmàtics identificats, ens centrarem en els que es relacionen amb algunes mesures concretes utilitzades. Les mesures són: la "fluïdesa comunicativa" (càlcul d'intencions comunicatives expressades per minut), la "flexibilitat pragmàtica" (nombre d'intencions comunicatives o de propostes comunicatives diferents), la "flexibilitat pragmàtica per minut" (nombre d'intencions comunicatives o de propostes comunicatives diferents expressades per minut), i la "types/token ratio" (divisió del nombre d'intencions comunicatives diferents pel total d'intencions comunicatives expressades).

En la parla de la mare s'observen uns increments clars en les tres primeres mesures a partir dels 809 mesos. Aquests canvis coincideixen amb els importants avenços comunicatius que realitzen els infants en aquesta edat, en què les seves propostes comunicatives són de forma indiscutible clarament intencionals. Els ajustos materns podrien estar reflectint un canvi qualitatiu en la percepció de la nena com a comunicadora intencional i com a intèrpret d'intencions -conseqüència de l'increment de la seva competència comunicativa-, que es traduiria en un augment dels actes comunicatius adreçats a ella, així com en una variabilitat més gran en les intencions comunicatives expressades per la mare en la interacció. Aquest canvi seria interpretable en termes de transformacions en el sistema de suport de l'adquisició del llenguatge (BRUNER, 1980) o com a una evidència de la naturalesa dinàmica de les interaccions a la zona de desenvolupament pròxim (VYGOTSKY, 1979). L'apreciació de part de l'adult d'un canvi en les competències de l'infant tindria conseqüències sobre la seva actuació en la interacció.

D'altra banda, la quarta mesura, la "types/tokens ratio" (divisió del nombre d'intencions comunicatives diferents pel total d'intencions comunicatives expressades) es manté força constant a les diferents sessions. Això indicaria una tendència de la mare a mantenir, per a cada sessió, una relació equilibrada entre el total d'intencions comunicatives expressades, o propostes comunicatives realitzades, i el total d'intencions comunicatives diferents. La tendència a la repetició, característica de la parla dirigida a l'infant, s'evidenciaria també en l'àmbit pragmàtic. En les sessions finals, quan la nena és més gran, la mare augmenta notòriament el nombre d'intencions comunicatives noves, però algunes d'elles es repeteixen reiteradament. De manera que la major fluïdesa comunicativa i la major flexibilitat pragmàtica, evidenciada de manera clara a partir dels 8 o 9 mesos, no suposa un increment en la types/token ratio. A les edats més avançades la mare emet més actes comunicatius per minut, és a dir, parla més a l'infant, i expressa una varietat més àmplia d'intencions comunicatives, però algunes d'aquestes presenten una tendència a la reiteració dins d'una mateixa sessió. El resultat és un equilibri en la diversitat pragmàtica 0 types/token ratio. Aquesta tendència pot ser interpretada en termes de suport adult o bastiment. Afegir riquesa pragmàtica a la interacció va acompanyat de la reiteració, i aquest equilibri facilitaria l'aprenentatge pragmàtic per part de l'infant.

\section{Conclusions}

D'entre les conclusions que es poden extreure del nostre treball, voldríem destacar que els resultats d'aquesta línia d'investigació es poden traduir en una invitació a l'anàlisi i la millora de les pràctiques que, com a adults, duem a terme en la nostra relació amb els infants. Les activitats que amb ells realitzem, la forma en què propiciem la seva participació, els ajuts que els atorguem per donar sentit a la situació interactiva, la parla que els adrecem, es poden constituir en elements facilitadors del procés de desenvolupament comunicatiu i lingüístic.

D'altra banda si, com creiem, l'adquisició del llenguatge es realitza sobre una base pragmàtica, és important que motivem els infants vers la comunicació, que generem en ells les ganes de fer propostes comunicatives i que fem intel-ligibles les nostres pròpies intencions vehiculades a través de la parla.

Crear contextos d'interacció que tinguin un sentit compartit pels seus participants 0 , en altres termes, construir definicions compartides de les situacions d'interacció, pot ser sens dubte un bon recurs per facilitar als infants la tasca d'aprendre a transmetre intencions i significats a través del llenguatge.

L'adult és molt més que el model a imitar per l'infant. L'adult construeix el llenguatge amb l'infant. Per tant, no només subministra models clars de parla, sinó models sobre com expressar intencions a través de la parla, és a dir, sobre com modificar l'estat mental (atencional i intencional) dels interlocutors. I les condicions creades per a la interacció han de fer possible que l'infant accedeixi als estats mentals dels seus interlocutors, a les seves metes i intencions. L'infant arribarà a expressar les seves pròpies intencions comunicatives a través de les regles que construirà en la interacció amb l'adult.

Finalment, assenyalarem que, pel que fa a afavorir el desenvolupament comunicatiu i lingüístic dels infants, la intuïció dels adults -pares o educadors- no sempre porta per camins adequats, ni tampoc sempre per camins equivocats. És en aquest sentit que es fa important i necessària la col·laboració entre educadors, professionals de l'assessorament $\mathrm{i}$ investigadors. 


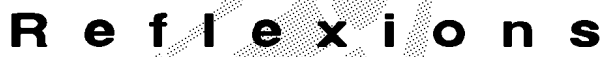

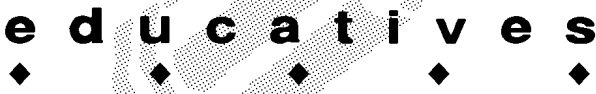

\section{Referències bibliogràfiques}

AUSTIN, J. L. How to do things with words. Edit. Oxford University Press. New York. 1962.

BRUNER, J. Intellectual autobiography. A G. LINDZEY (Ed.), History of Psychology in Autobiography. Edit. Freeman. San Francisco. 1980.

BRUNER, J. La parla dels infants. Editorial Eumo. Vic. 1985.

CARPENTER, M., NAGELL, K. i TOMASSELLO, M. Social cognition, joint attention and communicative competence from 9 to 15 months of age. «Monographs of the Society for Research in Child Development», 63 (1998).

GRICE, H. P. Logic and conversation. A P. COLE i J. L. MORGAN (Eds.), Syntax and semantics, Vol. 3: Speech acts. Edit. Academic Press. New York. 1975. Pàgs. 41-58.

KAYE, K. La vida mental y social del bebé. Cómo los padres crean personas. Editorial Paidós. Barcelona. 1986.

LOCK, A. The guided reinvention of language. Edit. Academic Press. London. 1980.

NINIO, A. On the fringes of the system: Children's acquisition of syntactically isolated forms at the onset of speech.
«First Language», 13 (1993) 291-313.

NINIO, A. i SNOW, C. E. Pragmatic Development. Edit. Westview Press. Oxford. 1996. Pàg. 4.

PAN, B. A., IMBENS-BAILEY, A., WINNER, K. i SNOW, C. Communicative intents expressed by parents in interaction with young children. «Merrill-Palmer Quarterly», 42 (1996) 248-266.

SEARLE, J. R. Speech acts. Edit. Cambridge University Press. Cambridge, Mas. 1969.

NOW, C. E. Development of conversation between mothers and babies. "Journal of Child Language», 4 (1977) 1-22.

SNOW, C. E., PAN, B. A., IMBENS-BAILEY, B. i HERMAN, J. Learning how to say what one means: a longitudinal study of children's speech act use. "Social Development», 5 (1996) 56-84.

TOMASELLO, M. The social-pragmatic theory of word learning. «Pragmatics», 10 (2000) 401-413.

VIGOTSKY, L. S. El desarrollo de los procesos psicológicos superiores. Edit. Crítica. Barcelona. 1979.

VIGOTSKY, L. S. Pensamiento y lenguaje. Edit. La Pléyade. Buenos Aires. 1977.

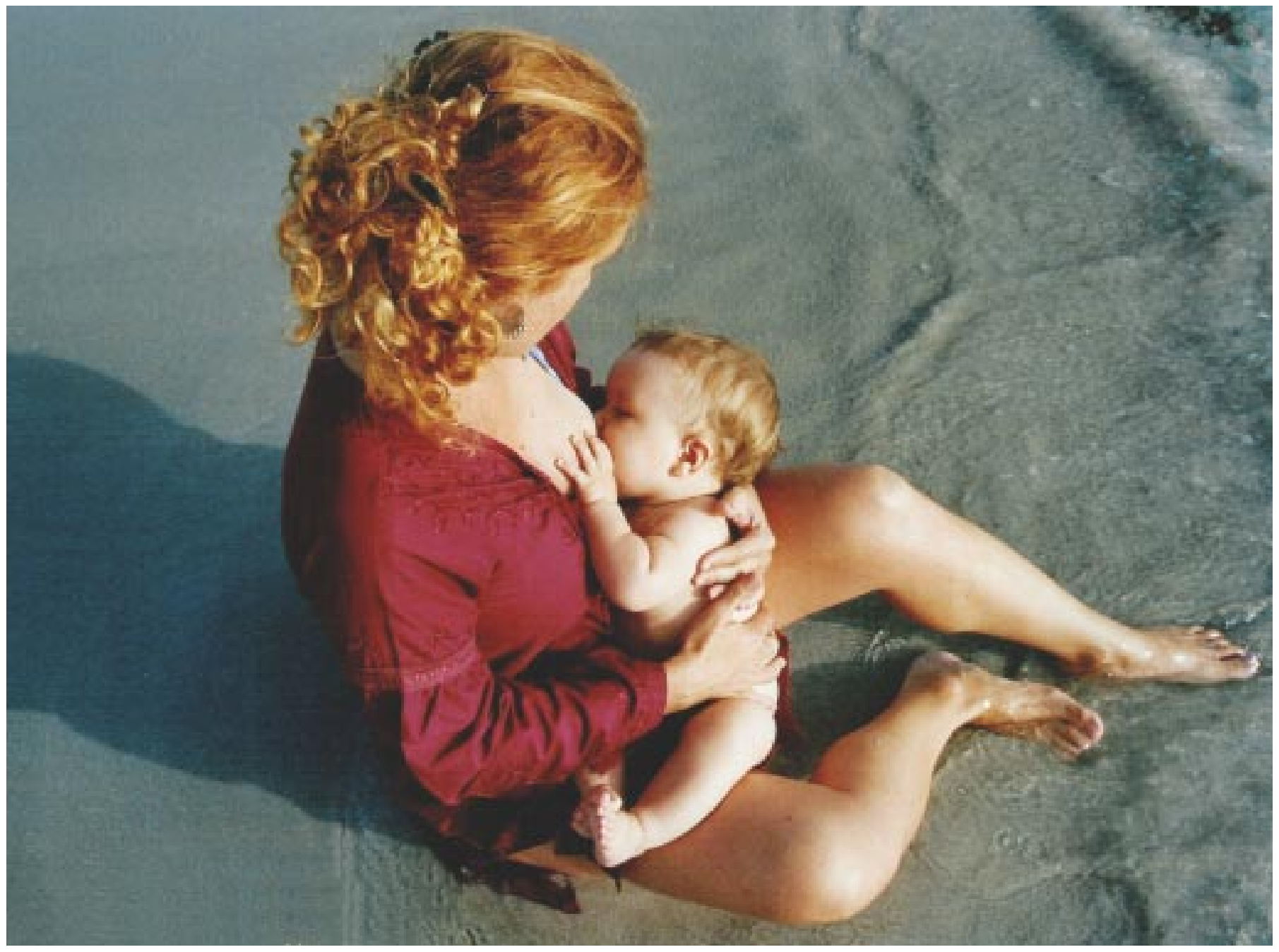

